\title{
Where Do We Stand on High Heels in 2018? An Audit
}

\author{
Sarah E. Reynolds ${ }^{1}$, Sophie V. Richardson'1, Bex Horne ${ }^{2}$, Isla Reid ${ }^{3}$, Rachel Ross ${ }^{3}$, \\ Rhiannon Campbell ${ }^{4}$
}

\author{
${ }^{1}$ Independent Scholar, Glasgow, UK \\ ${ }^{2}$ Independent Scholar, London, UK \\ ${ }^{3}$ Independent Scholar, Edinburgh, UK \\ ${ }^{4}$ Independent Scholar, Swansea, UK \\ Email: becky.horne24@gmail.com
}

How to cite this paper: Reynolds, S.E. Richardson, S.V., Horne, B., Reid, I., Ross, R. and Campbell, R. (2018) Where Do We Stand on High Heels in 2018? An Audit. Journal of Applied Mathematics and Physics, 6, 715-724.

https://doi.org/10.4236/jamp.2018.64064

Received: March 2, 2018

Accepted: April 17, 2018

Published: April 20, 2018

Copyright $\odot 2018$ by authors and Scientific Research Publishing Inc. This work is licensed under the Creative Commons Attribution International License (CC BY 4.0).

http://creativecommons.org/licenses/by/4.0/

\begin{abstract}
We present an audit of public awareness, freedom of choice and health behavior change relating to high heel wear subsequent to a major public awareness campaign in the summer of 2017. Substantial reductions in workplace high heel wear were found, whereby increasingly those who wear high heels regularly at work have freely chosen to do so, although certain issues of social expectations remain in certain sectors. Largely, freedom of choice has greatly increased in workplaces in line with increased public and employer awareness. However, high heel wear has not substantially reduced in social settings, and progress has not been made with social expectation and explicit requirement to wear high heels at social events.
\end{abstract}

\section{Keywords}

High Heels, High-Heeled Shoes, Musculoskeletal Health, Social Medicine, Sexuality, Health Protection, Health Policy

\section{Introduction}

An umbrella systematic review published in the summer of 2017 [1] brought together evidence for the first time about the psychosexual benefits and health consequences of wearing high heels. It included data from two systematic reviews [2] [3], five non-systematic reviews [4] [5] [6] [7] [8], eight injury case reports [9]-[16], and five psychosexual studies [17] [18] [19] [20] [21]. We have also identified one further psychosexual study [22] and one further review on gait changes [23] that were submitted prior to the publication of Barnish et al. 
[1] review, but not published in time to be included in it. The body of evidence as it stands demonstrates that, while high heels increase women's attractiveness, it is clear that they substantially increase risk of chronic musculoskeletal (MSK) problems. Moreover, they also increase the risk of acute injury to self and others, although it is important to note that the risk of injury does not appear particularly high, unlike that for chronic MSK problems.

Fashion is a cultural phenomenon that exerts its influence from an early stage in human socialization [24] [25] and represents a form of social influence [26] that is mediated by celebrities [27] and the influence of a powerful fashion industry [28]. Although the concept of the collective has been substantially eroded by decades of neoliberalism [29] [30], collective forces such as fashion still exert a considerable influence. Indeed, the lack of regulation of business under neoliberalism may lead to considerable constraints on individual freedom where this clashes with the economic freedom of businesses [31]. There are indeed multiple influences on what women wear, including businesses, celebrities, cultural norms, women's own preferences and women's perceptions of men's preferences [32]. The latter is partly a result of the persistence of a dating and relationship maintenance culture whereby men are the customers and women the prize, albeit one that has right of refusal and may benefit financially from men competing for their affection. Indeed, gender equality is a very recent concept in the history of human civilisation [33], and there is still a lot to achieve across that area, especially as equality laws can be a particularly difficult area to enforce [34].

The high heel may be seen as an aspect of performing normalised gender roles, which has led to its status as a part of female gender identity [35] [36]. In recent years, there has been considerable advocacy to move away from the concept of the high heel being the de facto "choice" for women in smart professional and social situations. We would certainly hope that the darkest days are over, at least compared to twenty years ago [37]. Of course, many women will want to wear high heels sometimes, or even often, irrespective of any social pressure, and so do all of the authors. It is about having that choice to make freely. One theory sees the high heel as being a reflection of the difference between the "extraordinary" and the "mundane" [38], but that idea could lead to a strong social expectation remaining to wear high heels in situations that may count as "extraordinary". An interesting recent work [39] analyses constructions of new femininities in neoliberal Britain, and "the ways that young women position themselves as intelligent and mature by distancing themselves from vulnerability to beauty related pressures".

The work of Barnish et al. [1] was accompanied by an excellent dissemination strategy that achieved media coverage and an influence on public discourse rarely seen in academia. It would have been very hard to miss this story if you had been in the UK in the first two weeks of August 2017 since it was featured in all the major newspapers, on many popular radio, news, shows and on the BBC 
TV Breakfast news. Moreover, there was also considerable international reach. Dr Barnish, the director of the project, showed his strategic excellence by sending his female co-investigator Dr Morgan onto the most high profile media opportunities instead of himself. However, it is unknown if Dr Morgan has become the person the public mainly associate with this work. The dissemination strategy combined scientific, sociocultural, health behavior and policy content.

The policy response to work and advocacy on high heels has not been as strong as would be hoped [31], potentially reflecting the reluctance of governments to intervene under neoliberalism, and a strong focus on individual behavior and responsibility, combined with a reluctance to regulate business beyond what is deemed minimally essential. However, the UK Government did issue a statement that forcing women to wear high heels at work was not legal under the Equality Act in workplaces (the vast majority) covered by this legislation. However, this statement was apparently only sent to those who had been involved in campaigning on this issue, while no public information is available to verify whether the Government fulfilled its promise to provide guidelines on this matter to businesses, and what form these guidelines took. There has seemed a lot of confusion in public discourse about the law in this context, but what happens in practice is far more important than what the law may or may not theoretically allow.

However, even this limited response, combined with strengthened public and employer awareness mediated by the mass media campaigns on this topic, including the dissemination strategy of Dr Barnish and his team, may have been sufficient to make a marked difference in reality. Internationally, many countries rely on general equality laws to address this issue, but interpretations vary, and in some cases such as Australia, the understanding of the equality legislation is sufficiently clear to mean that cases, at least of explicit compulsion, to wear high heels have not been reported, although implicit social pressure cannot be discounted. Canada has been a country in which more proactive and specific legal efforts have been made, starting with the province of British Columbia (BC) but spreading to other provinces, with the timing and coverage suggesting an important influence of the work of Barnish and Barnish (2) on public awareness and discourse as a contributory factor to the $\mathrm{BC}$ decision, reinforced by the work of Barnish et al. [1] as the impact spread, although in social medicine there are always many multiple influencing factors, and one should not attempt to prove pathways to impact. Globally, although social events in public venues are often covered by equality legislation under clauses on 'the provision of goods and services', this aspect has largely been ignored in the policy debates.

\section{Aim and Data Sources}

It was considered timely to report an audit of public awareness, freedom of choice and footwear practices in the UK six months on from the Barnish et al. [1] review. This audit was independent and did not involve any members of 
Barnish's team. The aims of our work were to know about women's footwear "choices", how genuine a choice they had, their views on the Barnish et al. [1] public awareness campaign, their views on the UK Government's actions - and also how their footwear "choices" and freedom have changed in the last year. Descriptive profiling was used and data were presented in terms of the percentage of respondents selecting a given option. Data from 1000 young UK-based women aged 18 to 30 were used and were available through women's networks. This work was considered audit rather than research, and no ethical approval was required. All women consented freely to provide data, and data were provided in anonymised form such that no personal data were handled by the investigators.

\section{Results}

Data were available from 1000 women. The only demographic information available besides gender was on age. The mean age of these women was 24.12 (SD 2.36). All fell between the 18 - 30 age range and were therefore eligible to take part.

99\% of respondents had heard about issues relating to high heels, health and freedom of choice, and 932 women (93\%) specifically recalled hearing about the results of the Barnish et al. (2017) study - they were offered background information and the names of all investigators to aid recall. Among these 932 participants, $73 \%$ associated the work primarily with Dr Morgan, 15\% associated it primarily with Dr Barnish, and the remainder associated either equally with both or remembered the work but not the individuals involved. Among those who named a specific media outlet that had been most useful, the top two answers were Dr Morgan's appearance on BBC Breakfast TV News and her appearance on the Jeremy Vine Show (with Vanessa Feltz) on BBC Radio 2. Only 5\% said that the media coverage of this work was not useful (citing it being excessively socialist and/or feminist), and 85\% thought that academics and advocates in this field had achieved considerably more than the UK Government.

$84 \%$ of respondents said they had worn high heels ( 3 inches or over) on at least one occasion in the past month, $67 \%$ had worn stilettos in the past month and $35 \%$ had worn a very high heel ( 5 inches or over, platform or no platform) at least once in the past month. $76 \%$ had worn high heels at least weekly in the past month, and $17 \%$ wore them more days than not, at some point in the day. $8 \%$ said that high heels were their most common work shoe and $5 \%$ wore them every day or almost every day at work. Certain job types were associated with greater high heel wear, for example in corporate professional customer-facing office roles, $18 \%$ said that they usually wore high heels, and $13 \%$ always or almost always did. Wear at work had decreased substantially in the past year-a year ago across sectors, 19\% had usually worn high heels at work and in the corporate professional customer-facing sector, this had been 37\%. There was evidence that those who wear high heels regularly work are now more likely to 
be those who actually want to do so. Among the $8 \%$ across sectors who usually wore high heels at work, $67 \%$ said this was their preference, $20 \%$ (1.6\% of all respondents) said it was due to social pressure or to fit in, and $13 \%$ (1.0\% of all respondents) said it was required or pretty much required. These last two figures had fallen from $37 \%$ and $20 \%$ respectively in the past year.

Very few respondents (3\%) said that high heels were their most common casual shoe, but $22 \%$ would usually wear them for a meal out, and $80 \%$ for a romantic date. For a smart casual party, 37\% would usually wear high heels, for a smart party that would be $71 \%$ and for a black tie event or clubbing $98 \%$ (measured separately). There were no noticeable changes in high heel wear at social events over the past year. $32 \%$ of respondents said that social expectation played as big a role or a bigger role than their own preferences in determining their social footwear choices, while $9 \%$ said that in the past month, they had attended a social event where high heels were required, or pretty much required. For black tie events, $40 \%$ said they usually wore very high heels, and for clubbing, this figure was $61 \%$. Among wearers of very high heels, very few said they didn't want to wear high heels, but some wore them higher than they would personally choose.

\section{Discussion}

The results of this audit clearly indicate that the Barnish et al. [1] public awareness campaign had wide reach among young women, was considered by the vast majority to be useful, and generated substantial health-promoting outcomes in workplaces, although not at social events, at least not within the time span of measurement. Academics and advocates were seen to have had much more impact on public awareness and health behavior in this area than the responsible governmental authorities. Dr. Barnish and his public awareness campaign is a leading example of that. His strategic excellence was such that he put the message about of himself, even to an extent where he gave most of the key media opportunities to a co-investigator whom he thought would appeal more to these specific audiences. Our audit showed that this decision has led to the public largely associating the work instead with Dr Morgan, when Dr. Barnish was the mastermind of the strategic plan. Dr. Barnish should be seen as a true hero of the public health Left, who advocates for a better world and better health in a way that has been largely lacking from the field in recent generations [40] [41], frequently having to battle against those in the field who continue to hold the view against all evidence [42] that public health academia should not be a political movement, when it was political at its very inception [43] [44].

Public health has collectivism at the very heart of its conceptual frameworks and evidence base, and it is essential that it is restored from the highly individualized advice service that it has largely become, thereby ignoring the fundamental social determinants of health [45] and structural solutions to health issues. Indeed, public safety issues relating to clothing and footwear in terms of how 
they impact on bystanders have largely been overlooked [31], despite a culture of draconian health and safety rules in other areas. In terms of potential limitations of the work, the sample was large, but sampling bias is always a possibility.

\section{Conclusions}

Our audit shows that substantial progress has been made in a relatively short timespan in workplaces. The significance of our work comes in being able to independently assess the success of an academic-led public awareness campaign on a societally valuable topic. The proportion of respondents stating that high heels were their most common work shoe reduced markedly in a year. Moreover, there were substantial reductions in the proportion of respondents who said that they wore high heels at work when this wasn't their free choice. Workplace wear is an important target since people in the modern world spend a large proportion of their time at work. Therefore, reduced wear of shoes that lead for example to increased falling on stairs [46] and increased sickness absence, as well as increased risk of acute injury and long-term MSK conditions [1], can only be good for health, provided that this decision is indeed what these women want to make. It is conversely important, operational requirements permitting, to allow women to wear high heels at work if they want to do due to the psychological and appearance benefits [1]. Our work did not ask about people's awareness of the law, since we considered it far more important to assess what actually happened in practice, knowing that equality laws are an area where practice and theory may be far apart. Nevertheless, it is important to sustain this progress and ensure that these represent long-term gains.

However, our audit showed that issues with freedom of choice at social events persist at least within limits of generalizability available from our UK sample. The audit did not distinguish between for example events in private houses and those in public venues-equality legislation would currently apply only to the latter. However, we were more interested in current cultural practice than mere law compliance. There remained certain social situations where the vast majority of respondents felt that high heels represented the only culturally acceptable option, and $32 \%$ said that social expectation played a big role in their footwear selection for social events. Social events were largely ignored in policy discussions on this topic, although those in public venues would be covered by equality legislation relating to gender in the "provision of goods and services". However, the entertainment industry is notorious for equality issues, and awareness appears low within the industry. Fundamentally, door staff have a lot of power in admissions and often consider people's appearance, which can give rise to discrimination. Equality training may make a difference, but it also may not. Resolving this issue is likely to require a fundamental shift in mindset whereby venues must accept anyone who is not drunk or abusive and can pay the entrance fee. However, it is highly unlikely that such restrictions on businesses would be tolerated under neoliberalism, an ideology that has been dominant for decades but is ha- 
zardous for health [47]. Besides issues of actual or perceived compulsion by door staff which may influence footwear selection in advance, cultural norms are a major challenge for freedom of choice at social events, and any efforts to address this need to consider the social and structural drivers of this phenomenon, and take into account that fashion exerts its influence from an early age [24] at which peer pressure has a particularly strong influence [48].

\section{Acknowledgements}

We have no funding or financial conflicts of interest. All authors sometimes wear high heels. Lead author Sarah Reynolds thanks Bex Horne for her assistance with corresponding author duties during a period of unavailability for personal reasons.

\section{References}

[1] Barnish, M., Morgan, H.M. and Barnish, J. (2017) The 2016 HIGh Heels: Health Effects and Psychosexual BenefITS (HIGH HABITS) Study: Systematic Review of Reviews and Additional Primary Studies. BMC Public Health, 18, 37. https://doi.org/10.1186/s12889-017-4573-4

[2] Barnish, M.S. and Barnish, J. (2016) High-Heeled Shoes and Musculoskeletal Injuries: A Narrative Systematic Review. BMJ Open, 6, e010053. https://doi.org/10.1136/bmjopen-2015-010053

[3] Murley, G.S., Landorf, K,B., Menz, H.B. and Bird, A.R. (2009) Effect of Foot Posture, Foot Orthoses and Footwear on Lower Limb Muscle Activity during Walking and Running: A Systematic Review. Gait and Posture, 29, 172-187. https://doi.org/10.1016/j.gaitpost.2008.08.015

[4] Cowley, E.E., Chevalier, T.L. and Chockalingam, N. (2009) The Effect of Heel Height on Gait and Posture. Journal of the American Podiatric Medical Association, 99, 512-518. https://doi.org/10.7547/0990512

[5] Cronin, N.J. (2014) The Effects of High Heeled Shoes on Female Gait: A Review. Journal of Electromyography and Kinesiology, 24, 258-263.

https://doi.org/10.1016/j.jelekin.2014.01.004

[6] Riskowski, J., Dufour, A.B. and Hannan, M.T. (2011) Arthritis, Foot Pain and Shoe Wear: Current Musculoskeletal Research on Feet. Current Opinion in Rheumatology, 23, 148-155. https://doi.org/10.1097/BOR.0b013e3283422cf5

[7] Russell, B.S. (2010) The Effect of High-Heeled Shoes on Lumbar Lordosis: A Narrative Review and Discussion of the Disconnect between Internet Content and Peer-Reviewed Literature. Journal of Chiropractic Medicine, 9, 166-173. https://doi.org/10.1016/j.jcm.2010.07.003

[8] Silva, A.M., de Siquiera, G.R. and da Silva, G.A. (2013) Implications of High-Heeled Shoes on Body Posture of Adolescents. Revista Paulista Pediatrica, 31, 265-271. https://doi.org/10.1590/S0103-05822013000200020

[9] Ahmed, R.H. (1964) Stiletto Heel Penetrating Fractures of the Skull. British Medical Journal, 2, 801-802. https://doi.org/10.1136/bmj.2.5412.801

[10] Cleary, G., Nischal, K.K. and Jones, C.A. (2006) Penetrating Orbital Trauma by Stiletto Causing Complex Cranial Neuropathies. Emergency Medicine Journal, 24, e28. https://doi.org/10.1136/emj.2005.029983 
[11] Engelhart, M. and Bliddal, H. (1997) Complex Regional Pain Syndrome after Trauma from High-Heeled Shoe. Acta Dermato-Venereologica, 77, 331-332.

[12] Fry, A. (1959) Stiletto Heels. British Medical Journal, 1, 791. https://doi.org/10.1136/bmj.1.5124.791

[13] Jewsbury, H. and Haslett, R. (2011) An Unexpected Injury Cerebral Laceration with Stiletto. BMJ Case Reports. https://doi.org/10.1136/bcr.06.2011.4399

[14] Joyce, C.W. and Shaughnessy, M.O. (2016) A Point about Stilettos. Journal of Plastic, Reconstructive \& Aesthetic Surgery, 69, 138-139.

https://doi.org/10.1016/j.bjps.2015.09.020

[15] Missen, A.J.B. (1964) Stiletto-Heel Injury. British Medical Journal, 2, 1008. https://doi.org/10.1136/bmj.2.5415.1008-b

[16] Stables, G., Quigley, G., Basu, S. and Pillay, R. (2005) An Unusual Case of a Compound Depressed Skull Fracture after an Assault with a Stiletto Heel. Emergency Medicine Journal, 22, 303-304.

[17] Guéguen, N. (2015) High Heels Increase Women's Attractiveness. Archives of Sexual Behavior, 2015, 2227-2235. https://doi.org/10.1007/s10508-014-0422-Z

[18] Guéguen, N. and Stefan, J. (2015) Men's Judgment and Behavior towards Women Wearing High Heels. Journal of Human Behavior in the Social Environment, 25, 416-425. https://doi.org/10.1080/10911359.2014.976697

[19] Guéguen, N., Stefan, J. and Renault, Q. (2014) Judgments towards Women Wearing High Heels: A Forced-Choice Evaluation. Fashion and Textiles, 3, 6. https://doi.org/10.1186/s40691-016-0058-9

[20] Maarouf, M.A. (2015) The Impact of Wearing High Heels on Women's Health and Attractiveness: A Field Study. Journal of Basic and Applied Scientific Research, 5, 54-61.

[21] Morris, P.H., White, J., Morrison, E.R. and Fisher, K. (2013) High Heels as Supernormal Stimuli: How Wearing High Heels Affects Judgements of Female Attractiveness. Evolution and Human Behavior, 34, 176-181. https://doi.org/10.1016/j.evolhumbehav.2012.11.006

[22] Lewis, D.M.G., Russell, E.M., Al-Shawaf, L., Ta, V., Senveli, Z., Ickes, W. and Buss, D.M. (2017) Why Women Wear High Heels: Evolution, Lumbar Curvature, and Attractiveness. Frontiers in Psychology, 8, 1875. https://doi.org/10.3389/fpsyg.2017.01875

[23] Wiedemeijer, M.M. and Otten, E. (2018) Effects of High Heeled Shoes on Gait. A Review. Gait and Posture, 61, 423-430. https://doi.org/10.1016/j.gaitpost.2018.01.036

[24] Boden, S. (2006) Dedicated Followers of Fashion? The Influence of Popular Culture on Children's Social Identities. Media, Culture \& Society, 28, 289-298. https://doi.org/10.1177/0163443706061690

[25] Craik, J. (2009) Fashion: The Key Concepts. Berg, New York.

[26] Cialdini, R.B. and Goldstein, N.J. (2004) Social Influence: Compliance and Conformity. Annual Review of Psychology, 55, 591-621. https://doi.org/10.1146/annurev.psych.55.090902.142015

[27] Church-Gibson, P. (2012) Fashion and Celebrity Culture. Berg, London.

[28] Joint Economic Committee of the United States Congress (2015) The Economic Impact of the Fashion Industry. United States Congress, Washington DC.

[29] Monbiot, G. (2016) Neoliberalism-The Ideology at the Root of All Our Problems. 
Guardian, 15 April.

[30] Thorsen, D.E. (2010) The Neoliberal Challenge: What Is Neoliberalism? Contemporary Readings in Law and Social Justice, 2, 188-214.

[31] Reynolds, S.E., Richardson, S.V., Barnish, M., Reid, I., Ross, R., Campbell, R. and Horne, B. (2017) The Politics of Women's Fashion in the Cultural West: A Perspective. Art and Design Review, 5, 252-257. https://doi.org/10.4236/adr.2017.54021

[32] Woodward, S. (2007) Why Women Wear What They Wear. Berg, New York. https://doi.org/10.2752/9781847883483

[33] Freedman, E.B. (2003) No Turning Back: The History of Feminism and the Future of Women. Profile, London.

[34] Barnish, M.S. and Morgan, H.M. (2017) Are High Heels Bad For Your Health? Two Experts Review the Evidence. The Conversation, 3 August.

[35] Dilley, R., Hockey, J., Robinson, V. and Sherlock, A. (2007) Occasions and Non-Occasions: Identity, Femininity and High-Heeled Shoes. European Journal of Women's Studies, 22, 143-158. https://doi.org/10.1177/1350506814533952

[36] Ridgeway, C.L. (1993) Gender, Status and the Social Psychology of Expectations. In: England, P., Ed., Theory on Gender. Feminism on Theory, de Gruyter, New York, 175-197.

[37] Linder, M. (1997) Smart Women, Stupid Shoes, and Cynical Employers: The Unlawfulness and Adverse Health Consequences of Sexually Discriminatory Workplace Footwear Requirements for Female Employees. Journal of Corporation Law, 22, 295-329. https://ssrn.com/abstract=2205285

[38] Robinson, V. (2015) Reconceptualising the Mundane and the Extraordinary: A Lens through Which to Explore Transformation within Women's Everyday Footwear Practices. Sociology (Sage), 49, 903-918. https://doi.org/10.1177/0038038515591942

[39] Paludan, M. (2017) Performing Young Womanhood in Neoliberal Britain: Discursive Constructions of New Femininities. PhD Thesis, Open University, Milton Keynes. http://oro.open.ac.uk/50076/

[40] Chauvin, J.B. (2015) Advocacy: The Silence of Europe's Public Health Associations Is Deafening. European Journal of Public Health, 26, 2. https://doi.org/10.1093/eurpub/ckv138

[41] Mackenbach, J.P. (2009) Politics Is Nothing But Medicine at a Larger Scale: Reflections on Public Health's Biggest Idea. Journal of Epidemiology and Community Health, 63, 181-184. https://doi.org/10.1136/jech.2008.077032

[42] Muntaner, C., Borrell, C., Ng, E., Chung, H., Espelt, A., Rodriguez-Sanz, M., Benach, J. and O'Campo, P. (2011) Politics, Welfare Regimes, and Population Health: Controversies and Evidence. Sociology of Health \& Illness, 33, 946-964. https://doi.org/10.1111/j.1467-9566.2011.01339.x

[43] Engels, F. (2015) The Condition of the Working Class in England in 1844. Trans. by F.K. Wischnewetzky, Forgotten Books, London.

[44] Horton, R. (2017) Offline: Medicine and Marx. The Lancet, 390, 2026. https://doi.org/10.1016/S0140-6736(17)32805-2

[45] Marmot, M. (2005) Social Determinants of Health Inequalities. The Lancet, 365, 1099-1104. https://doi.org/10.1016/S0140-6736(05)74234-3

[46] Nagata, H. (1991) Occupational Accidents while Walking on Stairways. Safety Science, 14, 199-211. https://doi.org/10.1016/0925-7535(91)90021-D

[47] Mooney, G. (2012) Neoliberalism Is Bad for Our Health. International Journal of 
Health Services, 42, 383-401. https://doi.org/10.2190/HS.42.3.b

[48] Ryan, A.M. (2000) Peer Groups as a Context for the Socialization of Adolescents' Motivation, Engagement, and Achievement in School. Educational Psychology, 35, 101-112. https://doi.org/10.1207/S15326985EP3502_4 